\title{
ELEMENTAL DISTRIBUTION IN LEAVES OF SPOROBOLUS VIRGINICUS USING NUCLEAR MICROPROBE
}

\section{Y. Naidoo and G. Naidoo}

School of Life \& Environmental Sciences, University of Durban-Westville, Private Bag X54001, Durban, 4000, South Africa

Sporobolus virginicus L. (Kunth) (Poaceae) is a halophytic, stoloniferous, perennial grass that is widely distributed along the coast of South Africa. The leaves of $S$. virginicus possess salt glands that actively secrete salt. The crystalline deposits over the glands, analysed by energy dispersive Xray microanalysis, were primarily $\mathrm{Na}^{+}$and $\mathrm{Cl}^{-}$. Other ions such as $\mathrm{K}^{+}, \mathrm{Ca}^{2+}$ and $\mathrm{Mg}^{2+}$ were also detected in the deposits. Considerable research has been undertaken on the ultrastructure [1] and physiology [2] of the salt glands of these plants. Information on the elemental distribution of $\mathrm{Na}^{+}$ and $\mathrm{Cl}^{-}$could provide clues on the localisation and pathway of ion transport and contribute to an understanding of salt tolerance mechanisms in halophytes. In the present study, the subcellular distribution of elements in the leaf blade tissues was determined by means of nuclear microprobe analysis.

Cross sections of the mid-region of living flag leaves of $S$. virginicus were cut by hand with dry razor blades, frozen rapidly in isopentane, cooled with liquid nitrogen and freeze-dried in an Edwards Modulyo Freeze Dryer at $-60^{\circ} \mathrm{C}$ at a vacuum of $10^{-2}$ Torr for $5 \mathrm{~d}$. Leaf sections were mounted on aluminium target frames and coated with carbon for $\pm 5 \mathrm{~s}$ to give a final coating of about $10 \mathrm{~nm}$. Elemental distribution maps of $\mathrm{Na}^{+}, \mathrm{Cl}^{-}, \mathrm{K}^{+}, \mathrm{Mg}^{2+}$ and $\mathrm{Ca}^{2+}$ were made using the true elemental imaging system (Dynamic Analysis) of the National Accelerator Centre Van der Graaf nuclear microprobe. Two complimentary techniques, Proton Induced X-ray Emission (PIXE) and Proton Back-Scattering (BS) were performed simultaneously, using $0.6 \mathrm{MeV}$ protons with a beam spot of 4 x $4 \mu \mathrm{m}$. In addition, pieces of leaf blade material were rapidly quenched in liquid nitrogen and freeze-dried at $-60^{\circ} \mathrm{C}$ for $72 \mathrm{~h}$, coated with gold and viewed in a Philips SEM 500 at $12 \mathrm{kV}$. Some leaf material was also embedded in historesin for general anatomical studies.

The leaf surface of $S$. virginicus is undulating with clearly defined adaxial ridges alternating with deep grooves (Fig. 1). On the ridges are numerous trichomes (Fig. 1), as well as secreted salts. Salt glands occur predominantly on the adaxial surface and are uniformly localised along the flanks of the veins, just below the sclerenchymatous cap (Fig. 2). The salt glands are club-shaped and bicellular. A single row of glands occurs in the grooves of the abaxial surface while two longitudinal rows of glands are located on the flanks of each vein on the adaxial surface. The leaf blades exhibit typical $\mathrm{C}_{4}$ or Kranz anatomy. The vascular bundles are of two different sizes, small and large, the latter representing the major veins. Large vascular bundles are surrounded by a double bundle sheath. Around the vascular bundles are 2-3 rows of loosely arranged mesophyll cells (Fig. 2). PIXE and BS analysis revealed that $\mathrm{Cl}^{-}$was present in all leaf tissues, the concentration being highest in the mesophyll tissue on the adaxial side in close proximity to the salt glands (Fig. 3). High concentrations of $\mathrm{Cl}^{-}$were also found on the abaxial side of the leaf in close proximity to the groove where glands are located. Sodium, like $\mathrm{Cl}^{-}$, was distributed throughout the leaf blade, concentrations being highest on adaxial and abaxial leaf tissues where glands occur (Fig. 4). There was heavy enrichment of $\mathrm{K}^{+}$in all leaf tissues (Fig. 5). Calcium and $\mathrm{Mg}^{2+}$ were 
present in lower concentration than those of $\mathrm{Cl}^{-}, \mathrm{Na}^{+}$and $\mathrm{K}^{+}$. This study demonstrated that $\mathrm{Na}^{+}$and $\mathrm{Cl}^{-}$occur in high concentrations in close proximity to the salt glands.

\section{References}

[1] Y. Naidoo and G. Naidoo, South African J. Botany 64 (3) (1998) 198.

[2] G. Naidoo and Y.Naidoo, Flora 193 (1998) 337.
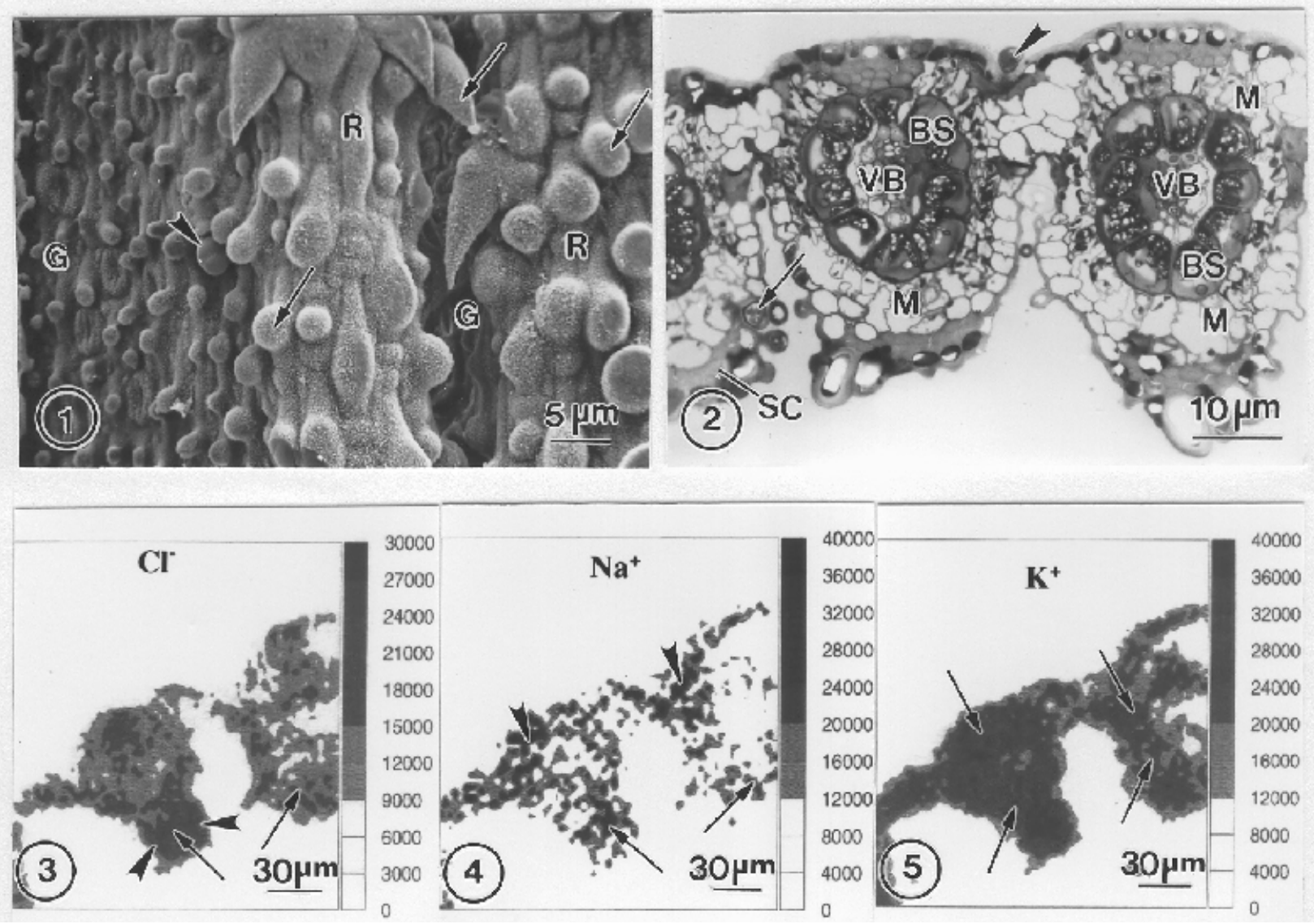

Fig. 1. SEM image of leaf surface showing trichromes, (arrows), ridges (R) and grooves (G), note bicellular salt gland (arrowhead) on flank of vein.

Fig. 2. LM of cross section of leaf blade showing adaxial gland (arrow) inserted under sclerenchyma cap (SC) and abaxial gland (arrowhead). Note radiate cells of outer bundle sheath (BS) and loosely arranged mesophyll cells (M) around vascular bundles (VB).

Fig. 3. $\mathrm{Cl}^{-}$map showing high concentration in mesophyll tissue (arrows) close to salt glands on adaxial surface (arrowheads).

Fig. 4. $\mathrm{Na}^{+}$map showing distribution in leaf blade with higher concentrations on adaxial (arrows) and abaxial (arrowheads) leaf tissues.

Fig. 5. $\mathrm{K}^{+}$map depicting heavy enrichment in all leaf tissues (arrows).

Scales shown on the right side of every map are in $\mu \mathrm{g} / \mathrm{g}$ and represent true elemental concentrations found by Dynamic Analysis. 